\title{
OSCILLATORY SOLUTIONS FOR A GENERALIZED SUBLINEAR SECOND ORDER DIFFERENTIAL EQUATION
}

\author{
J. W. HEIDEL ${ }^{1}$ AND I. T. KIGURADZE
}

\begin{abstract}
A criterion is given for the existence of oscillatory solutions for equation (1) below which generalizes a recent result for the sublinear case of $\left(1^{\prime}\right)$. The present theorem is the analogue of a result of Izjumova for the generalized superlinear case.
\end{abstract}

We consider the question of the existence of oscillatory solutions of the equation

$$
u^{\prime \prime}+f(t, u)=0
$$

where the function $f(t, u)$ is defined and continuous in the region $0 \leqq t<\infty$, $-\infty<u<\infty$, and $f(t, 0) \equiv 0$.

Equation (1) is a generalization of

$$
u^{\prime \prime}+q(t) u^{\gamma}=0
$$

which is called superlinear if $\gamma>1$ and sublinear if $0<\gamma<1$. A criterion for the existence of oscillatory solutions for $\left(1^{\prime}\right)$ in the superlinear case was first given by Jasny [6] and Kurzweil [8]. A short proof of the JasnyKurzweil theorem was given by the second author [7]. The theorem was then generalized to (1) in several directions, first by Izjumova [5] and then by Coffman and Wong [2], [3].

The analogue of the Jasny-Kurzweil result for the sublinear case has recently been established by Hinton and the first author [4] and Chiou [1]. The purpose of the present note is to generalize this result by giving the analogue of Izjumova's theorem.

THEOREM. Suppose that for every fixed $x>0$, the function

$$
\phi(t, x)=t^{3 / 2} f\left(t, t^{1 / 2} x\right)
$$

is nonnegative, continuously differentiable, and nondecreasing in $t$ in the

Received by the editors May 8, 1972 and, in revised form, June 30, 1972.

AMS (MOS) subject classifications (1970). Primary 34C10.

Key words and phrases. Oscillation, sublinear, nonlinear differential equations.

${ }^{1}$ Supported by a University of Tennessee Faculty Research Grant.

(C) American Mathematical Society 1973 
interval $\left[t_{0}, \infty\right)$ where $t_{0}>0$. If, moreover, $\phi(t,-x)=-\phi(t, x)$ and

$$
\liminf _{x \rightarrow 0}\left(\phi\left(t_{0}, x\right) / x\right)>\frac{1}{4},
$$

then equation (1) has at least one nonsingular oscillatory solution.

Proof. Let $\Phi(t, x)=2 \int_{0}^{x} \phi(t, s) d s$.

In view of (3), positive constants $\gamma$ and $\delta$ can be found such that

$$
\phi\left(t_{0}, x\right)>x(1+\gamma) / 4 \text { for } 0<x \leqq \delta
$$

and

$$
\Phi\left(t_{0}, x\right)>x^{2}(1+\gamma) / 4 \text { for } 0<x \leqq \delta .
$$

Let $u(t)$ be a solution of equation (1) which satisfies the initial condition

$$
u\left(t_{0}\right)=0, \quad 0<t_{0} u^{\prime 2}\left(t_{0}\right)<\delta^{2} \gamma / 4,
$$

at $t_{0}$.

Multiplying both sides of equation (1) by $t^{3 / 2}\left(t^{-1 / 2} u(t)\right)^{\prime}$ and integrating from $t_{0}$ to $t$, we obtain

(7) $\left(\sqrt{ } t u^{\prime}-u / 2 \sqrt{ } t\right)^{2}+\Phi(t, v(t))-\frac{1}{4} v^{2}(t)=t_{0} u^{\prime 2}\left(t_{0}\right)+\int_{t_{0}}^{t} \frac{\partial \Phi(\tau, v(\tau))}{\partial \tau} d \tau$, where $v(t)=t^{-1 / 2}|u(t)|$.

Let $w(t)=\max \left\{v(s): t_{0} \leqq s \leqq t\right\}$.

Since $\partial \Phi(t, x) / \partial t$ is nondecreasing with respect to $x$ in the interval $\left(t_{0}, \infty\right)$ we have

$$
\int_{t_{0}}^{t} \frac{\partial \Phi(\tau, v(\tau))}{\partial \tau} d \tau \leqq \int_{t_{0}}^{t} \frac{\partial \Phi(\tau, w(t))}{\partial \tau} d \tau=\Phi(t, w(t))-\Phi\left(t_{0}, w(t)\right) .
$$

Therefore from (6), (7) and (8) it follows that

$$
\Phi\left(t_{0}, w(t)\right)-\frac{1}{4} w^{2}(t)<\frac{\delta^{2} \gamma}{4}+\Phi(t, w(t))-\Phi(t, v(t)) .
$$

Since $w\left(t_{0}\right)=0$ and $w(t) \geqq 0$ for $t \geqq t_{0}$, it is clear that

$$
0 \leqq w(t)<\delta
$$

in some right neighborhood of $t_{0}$. We will now show that (10) holds for all $t \geqq t_{0}$. Suppose to the contrary that there is a $t_{1}>t_{0}$ such that $w\left(t_{1}\right)=\delta$ and that $t_{1}$ is the smallest such value of $t$. Then $w\left(t_{1}\right)=v\left(t_{1}\right)$ and so from (5) and (9) it follows that

$$
(\gamma / 4) w^{2}\left(t_{1}\right)<\delta^{2} \gamma / 4,
$$

a contradiction. 
Consequently

$$
t^{-1 / 2}|u(t)|=v(t)<\delta \quad \text { for } t \geqq t_{0} .
$$

Thus we have proven that $u(t)$ is extendable on the whole interval $\left[t_{0}, \infty\right)$ and satisfies the inequality (11). On the other hand, from (7) it is clear that $|u(t)|+\left|u^{\prime}(t)\right| \neq 0$ for $t \geqq t_{0}$. Consequently, $u(t)$ is a nonsingular solution.

We will prove that $u(t)$ is oscillatory. Suppose to the contrary that for some $t^{*}>t_{0}, u(t) \neq 0$ for $t>t^{*}$.

Then in the interval $\left[t^{*},+\infty\right)$ equation (1) can be written in the following form: $u^{\prime \prime}+a(t) u=0$, where $a(t)=t^{-2}[\phi(t, v(t))] / v(t)$.

According to (4) and (11),

$$
a(t) \geqq \frac{\phi\left(t_{0}, v(t)\right)}{v(t)} t^{-2} \geqq \frac{1+\gamma}{4} t^{-2} \text { for } t \geqq t^{*} .
$$

Thus, according to Kneser's theorem, $u(t)$ is an oscillatory function. The contradiction thus obtained proves the theorem.

Corollary ([1]). If $0<\gamma<1, q(t) t^{(\gamma+3) / 2}>0$ and $\left(q(t) t^{(\gamma+3) / 2}\right) d / d t \geqq 0$, then every solution $u(t)$ of $\left(1^{\prime}\right)$ such that $u\left(t_{0}\right)=0$ and $\left|u^{\prime}\left(t_{0}\right)\right|$ is sufficiently small is oscillatory.

\section{REFERENCES}

1. Kuo-liang Chiou, The existence of oscillatory solutions for the equation $d^{2} y / d t^{2}+$ $q(t) y^{r}=0,0<r<1$, Proc. Amer. Math. Soc. 35 (1972), 120-122.

2. C. V. Coffman and J. S. W. Wong, On a second order nonlinear oscillation problem, Trans. Amer. Math. Soc. 147 (1970), 357-366. MR 41 \#2123.

3. - Oscillation and nonoscillation of solutions of generalized Emden-Fowler equations, Trans. Amer. Math. Soc. 167 (1972), 399-434.

4. J. W. Heidel and Don B. Hinton, The existence of oscillatory solutions for a nonlinear differential equation, SIAM J. Math. Anal. 3 (1972), 344-351.

5. D. V. Izjumova, Conditions for the oscillatory and non-oscillatory nature of nonlinear differential equations of second order, Differencial'nye Uravnenija 2 (1966), 15721586=Differential Equations 2 (1966), 814-821. MR 35 \#476.

6. M. Jasny, On the existence of an oscillating solution of the nonlinear differential equation of the second order $y^{\prime \prime}+f(x) y^{2 n-1}=0, f(x)>0$, Casopis Pěst. Mat. 85 (1960), 78-83. (Russian) MR 26 \#408.

7. I. T. Kiguradze, On the conditions for oscillation of solutions of the differential equation $u^{\prime \prime}+a(t)|u|^{n} \operatorname{sgn} u=0$, Casopis Pěst. Mat. 87 (1962), 492-495. (Russian) MR 31 \#6026.

8. J. Kurzweil, $A$ note on oscillatory solutions of the equation $y^{\prime \prime}+f(x) y^{2 n-1}=0$, Casopis Pěst. Mat. 85 (1960), 357-358. (Russian) MR 23 \#A3322.

Department of Mathematics, University of Tennessee, Knoxville, Tennessee 37916

Institute of Applied Mathematics, Tbilisi State University, Tbilisi, U.S.S.R. 